\title{
Making deservingness of the unemployed conditional: Changes in public support for the conditionality of unemployment benefits
}

Christopher Buss, Bernhard Ebbinghaus and Elias Naumann

SFB 884 'Political Economy of Reforms', University of Mannheim PREPRINT JULY 2016

To be published in an edited volume by:

W. van Oorschot, F. Roosma, B. Meuleman, \& T. Reeskens (Eds.),

The Social Legitimacy of Targeted Welfare: Attitudes to Welfare Deservingness.

Cheltenham: Edward Elgar Publishing, 2017.

\begin{abstract}
Since the 1990s, stricter conditions for the (long-term) unemployed to receive benefits have been on the 'activation' agenda. However, policymakers are constrained in their reform efforts by the economic and fiscal situation, the pre-existing institutional contexts and public opinion. This cross-national and longitudinal study investigates whether the social legitimacy of benefit obligations for the unemployed is affected by the changing economic situation and the varying institutional context. We use data from the European Values Survey, a repeated cross-sectional survey that was conducted in 1990, 1999 and 2008 in 23 European countries. Support for the conditionality of unemployment benefits is measured with an item that asks whether people who are unemployed should have to take any job available. We find that the main economic indicators - economic growth and the unemployment rate - are significantly related to support for conditionality. People living in wealthier countries are more likely to be in favour of conditionality, whereas a high unemployment rate reduces such support. With regard to institutional features, we find some support for the assumption that people in welfare states with more generous social policies prefer stricter conditionality for access, in order to protect the generous benefits against any misuse.
\end{abstract}




\section{Introduction}

Stricter conditions for the unemployed to receive benefits have been on the political agenda for more than two decades ever since the 'activation turn'. Although the welfare state has persisted due to its high popularity (Brooks and Manza, 2007), there have been inroads in public opinion on making benefits more conditional, in particular for the long-term unemployed. Indeed, previous research suggests that the population generally supports conditions attached to social benefits (Houtman, 1997; Larsen, 2008): social rights are granted to the needy not without obligations (Marshall, 1950). Attributions of (un)deservingness are of particular relevance in individual attitudes towards social policy.

The relationship between citizens and the welfare state can be seen as a social exchange (Mau, 2003) or a 'social contract', the conditions of which are circumscribed in its formal legal regulations and informal institutions (Houtman, 1997). This might be most obvious in the field of pension policies, where the term 'generational contract' has been used to legitimize pay-as-you-go pension arrangements that bind multiple generations (Myles and Pierson, 2001). Such social institutions are also relevant in other social policy areas. For example, the welfare state provides protection against unemployment risks, but in exchange, everyone who is able to work is expected to seek employment. This social contract between payers and recipients defines - formally and informally - the social rights of the unemployed to social protection when in need, but also stipulates that recipients need to seek work in due time (Houtman, 1997).

Literature dealing with public attitudes towards the welfare state (see Svallfors, 2010) has tended to focus on social rights as specific benefit entitlements. In an analysis of a majority of surveys, two of the standard question items used ask about the government's responsibility to ensure a reasonable standard of living for the unemployed - with possible answers from definitive support to the opposite - (Blekesaune and Quedagno, 2003; Naumann et al., 2016; van Oorschot and Meuleman, 2014) and whether the state should spend (much) more or (much) less on unemployment benefits (Fraile and Ferrer, 2005; Svallfors, 2011). Following the political shift towards activation, research has increasingly focused on the obligations that are attached to social rights (Dwyer, 2004) and the role of reciprocity (Mau, 2003). 
Surprisingly, to our knowledge there is no comparative empirical study on public support for benefit obligations, and existing research is restricted to single-country studies, for example covering the Netherlands (Achterberg et al., 2014; see also Jeene and Roosma in this volume) and Australia (Larsen, 2008). Therefore, it remains an unresolved question how public opinion on obligations changes in reaction to augmented reform pressures, that is, to increasing unemployment rates and public deficits. Is support for the conditionality of unemployment benefits higher or lower in times of mass unemployment compared with times when it is easier to find a job? Are citizens in favour of conditionality when they assume that they are unlikely to need these benefits? Furthermore, are those in need always against any obligations?

In this chapter, we investigate how the social legitimacy of benefit obligations for the unemployed has changed over time across Europe. We are particularly interested in whether changes in the economic and/or political contexts are reflected by respective variations in public support for benefit obligations. The relevance of investigating attitude change stems from its potential impact on subsequent reforms, because policymakers are constrained in their policy choices; not only by historically derived institutional contexts, but also by the reaction of public opinion to policies that already exist (Burstein, 2003).

Our contribution to existing research on deservingness perceptions and popular attitudes towards conditionality for unemployment benefits is threefold. First, we extend the usual focus on social benefit rights by investigating attitudes towards the responsibilities of recipients, that is, the social legitimacy of benefit obligations. Second, we aim to move beyond a static cross-sectional analysis and provide a comparative study of how public support for benefit obligations has changed across Europe, studying 23 countries over the last two decades. Lastly, we extend the regional coverage beyond Western-European countries by also including post-communist Eastern-European countries and other new EU member states in our analysis.

\section{Theory and hypotheses}

Two basic motivations help explain individual attitudes towards social policy: self-interest and the perceived deservingness of those in need (Jæger, 2006). The rational self-interest 
argument suggests that individuals who depend on state benefits, or are at risk of relying on assistance in the future, are more in favour of generous policies (Margalit, 2013; Naumann et al., 2016). In line with this argument, the unemployed tend to be more critical towards the expectation to accept any job offer or towards stricter monitoring of their job search efforts (Larsen, 2008; Achterberg et al., 2014). Conversely, those people that do not expect to become unemployed but are net payers for such social benefits are more likely to be in favour of stricter conditions.

A solidaristic value orientation towards the needy is dependent on the public image of the recipient group, therefore the perceptions of deservingness shape individual attitudes towards making social benefits more or less conditional. In this vein, welfare state support depends on how deserving the respective beneficiaries are of help (see the CARIN criteria in the introduction of this volume). Several studies provide evidence that the unemployed are seen as less deserving compared with other beneficiary groups such as the sick and the elderly (van Oorschot, 2006; see also Laenen and Meuleman in this volume). Most people also agree that benefit recipients should do something in return (for example, work in the community) for their benefits (Larsen, 2008). However, support for stricter conditions and sanctions is weaker when the disabled or the older unemployed are affected (Houtman, 1997; see also Jeene and Roosma in this volume).

In this contribution, we are primarily interested in how socioeconomic development and the politically induced institutional context affect aggregated public support for conditionality. Based on a cross-national comparison and longitudinal analysis, we study whether variations across countries and over time can explain support for the conditionality of unemployment benefits.

We propose two mechanisms that could mediate the effect of the economic and the institutional context on public attitudes. First, we argue that the context influences both the self-interest calculations and the public's image of the unemployed, in particular the perceived deservingness of this group. Second, in line with the policy feedback thesis, we argue that existing social policies influence public attitudes, thereby reshaping preferences and interests. Several mechanisms have been proposed for policy feedback effects, pointing most prominently at distributive mechanisms and interpretive effects (see for example 
Pierson, 1993; Kumlin and Stadelmann-Steffen, 2014). Policies can therefore generate their own support (positive feedback) or undermine themselves (negative feedback).

\subsection{The economic context}

How the economic context, in particular the business cycle, affects welfare attitudes is a longstanding question in this research field. Several studies examine the consequences of economic downturn and rising unemployment for attitudes towards the unemployed (Jeene et al., 2014; van Oorschot and Meuleman, 2014). There is debate, however, concerning the direction of this relationship. Do economic downturns increase or decrease support for generous social policies?

On the one hand, some scholars argue that support for the welfare state (in particular, unemployment benefits) is eroded in times of high unemployment and economic downturn. The importance of individual self-interest might increase, because people care more about themselves in hard times (Durr, 1993). In particular, increasing unemployment rates might raise concerns about the higher costs of public welfare. Tax payers (including those contributing to social insurance) might oppose any further increase in public expenditure and instead accept benefit retrenchment, including stricter conditions for benefit recipients. Furthermore, the perceived deservingness of the unemployed might decrease in hard times if expectations prevail that the jobless need to contribute something in return for receiving these unemployment benefits. Accordingly, the two motivations lead to our first hypothesis:

H1a: Support for the conditionality of unemployment benefits is higher in economic downturns.

On the other hand, some arguments point to the opposite effect of the business cycle. In times of low unemployment, the jobless might be considered as being more responsible for their situation (based on the control principle), and the population could see stricter conditions for benefits as a promising way to increase the motivation to seek work. When the labour market is in a worse situation, it seems plausible that people could see the unemployed as more deserving, because they are less to blame for their position (Jeene et al., 2014). Economic downturns also increase the (perceived) risk of future job loss among the employed. Out of self-interest based on the perceived or objective increased likelihood of becoming unemployed, those in work might reduce their support for the strict 
conditionality of unemployment benefits (Fraile and Ferrer, 2005). From this perspective, high unemployment rates and economic downturns increase the respondent's deservingness perception vis-à-vis the unemployed, making them more lenient with regard to conditionality. Therefore, in contrast to our first hypothesis:

H1b: Support for the conditionality of unemployment benefits is lower in economic downturns.

With regard to the right to benefits, existing empirical evidence mainly supports the latter argument: in times of economic downturns, deservingness attribution towards the jobless, and therefore support for unemployment benefits, is higher (Fraile and Ferrer, 2005; Jeene and van Oorschot, 2014). However, Jeene and colleagues (2014) argue that economic growth and unemployment have independent effects on attitudes in the short term. Using longitudinal data from the Netherlands, they provide evidence that both economic growth and high unemployment rates increase the likelihood of attributing more deservingness to needy groups.

\subsection{The institutional context}

In addition to the economic situation, institutional arrangements play an important role in shaping attitudes (Hall and Taylor, 1996; Larsen, 2007; Wendt et al., 2011; see also Uunk and van Oorschot in this volume). Given the activation turn in labour-market policies, we are particularly interested in whether these policy changes (activation reforms) are reflected by changes in public opinion. In addition to benefit conditionality, the generosity of unemployment benefits and the proportion of the population eligible for benefits are key elements of the institutional context.

Access to benefits has always been limited (for example, required contribution periods and restricted benefit duration), and further conditions (for example, sanctioning voluntary unemployment) have often been applied (Clasen and Clegg, 2011). The OECD Jobs Study of 1994 most prominently recommended a deregulation of labour markets in Europe, advocating the flexible labour-market model of the USA. The workfare policies in the USA in particular were seen as examples for Europe: unemployment was no longer a 'status right' for all citizens, but a contractual relationship that stipulated benefit rights in exchange for the duty to seek work (Handler, 2003). Across Europe, reforms in the area of 
unemployment protection and labour-market policy shifted towards an activation paradigm (Weishaupt, 2011), including increased sanctions and conditionality criteria for receiving unemployment benefits. Conditionality was enforced particularly for minimum income benefits for the long-term unemployed. Activation policies therefore basically change how welfare benefits and benefit receipt are construed.

Interpretive feedback effects (Pierson, 1993) suggest that policies frame public perceptions of societal problems and potential solutions. For example, strict regulations concerning the access to unemployment benefits might shift the focus onto individual behaviour and selfdiscipline (Gusmano et al., 2002). Accordingly, as conditions for entitlement to unemployment benefits become more common over the years, positive feedback effects might lead to a greater acceptance of these measures over time. Therefore:

H2: In countries with strict conditionality for receiving unemployment benefits, support for these measures is higher.

A second aspect of the institutional context concerns the generosity of benefits, measured by the replacement rate and spending on unemployment benefits. Higher unemployment benefits alleviate the material needs of the jobless, allow a longer search for appropriate reemployment (Estevez-Abe et al., 2001) and are legitimated as providing a reasonable standard of living for the involuntary unemployed (Fridberg and Ploug, 2000). At the same time, we assume that benefit generosity alters the deservingness perception of the unemployed by increasing expectations that the jobless reciprocate the 'favour' of unemployment benefits and accept any job offered to them. Hence, we expect that greater social protection for the jobless leads to a higher demand to attach obligations to unemployment benefits. Accordingly:

H3: Support for the conditionality of unemployment benefits is higher when benefits are generous.

Countries differ widely with regard to the proportion of the population eligible for unemployment benefits. Some groups (such as the self-employed) are not covered and others do not meet the criteria to receive benefits. When more people are covered by unemployment benefits, a higher proportion of the population is also potentially affected by the conditions for unemployment benefits. Because unemployment benefits, in particular 
minimum income systems, are partly tax funded in many countries, we argue that those who are not covered by the system have a stronger interest in restricting access. Based on this self-interest argument, we assume stronger support for conditions for unemployment benefits in countries with a low coverage of the population. Therefore:

H4: The higher the proportion of the population that is covered by unemployment benefits, the weaker will be the support for conditions for unemployment benefits.

\section{Data and methods}

We use data from the European Values Study (EVS), a repeated cross-sectional international survey that was conducted in 1990, 1999 and 2008. ${ }^{1}$ The EVS includes 23 countries, about half of them from Eastern Europe, and provides data for the three points in time. After listwise deletion of 9.3 per cent of the respondents due to missing data on the dependent variable, we are left with 90360 respondents. These individuals are clustered within 69 country-years and 23 countries. Sample sizes range from 559 in Finland, to 3222 in Germany in 1990.

\subsection{Dependent variable}

Support for the conditionality of unemployment benefits is measured on a 1 to 10 scale, using an item that asks whether an unemployed person should take any job available in order not to lose their unemployment benefits (10) or whether the unemployed should have the right to refuse a job they do not want without consequences for their benefits (1). This item captures two related aspects of labour-market policy, namely the strictness of obligations for benefits and the appropriate sanction if benefit recipients fail to comply with these conditions.

\subsection{Country-level indicators}

In order to explain the cross-national variation, we use nine indicators based on different international data sources (OECD, ILO and World Bank; see Table 1 for details). Our key indicators for the economic context $(\mathrm{H} 1 \mathrm{a}, \mathrm{H} 1 \mathrm{~b})$ are economic development (gross domestic product, GDP) and the unemployment rate. These indicators are included in absolute terms as well as by their rate of change over the last three years. As Jeene and colleagues (2014) show, the prevailing economic situation leads to short-term fluctuations in public opinion. 
We include the logarithm of the inflation-corrected GDP to account for the fact that economic prosperity might have a non-linear effect.

In line with our theoretical expectations, we investigate the relationship between attitudes and three institutional aspects of unemployment benefits: conditionality (H2), generosity (H3) and coverage (H4). Benefit generosity is assessed using two measurements. First, we use the 'replacement rate', which indicates the proportion of previous earnings provided by unemployment benefits. Second, 'spending' on passive labour market policies per unemployed in relation to the GDP illustrates the proportion of economic resources that are dedicated relative to the number of unemployed. 'Coverage' measures the proportion of the workforce that is insured against unemployment (see Scruggs et al., 2014).

In contrast to these measurements, few indicators are available to assess the conditionality of unemployment benefits. Knotz and Nelson (2015) use the factors of suitable employment, job-search requirements and the strictness of sanctions as indicators for conditionality. We argue that these specific factors might not be sufficiently known throughout society to be strongly related to public opinion. For this reason, we use two, more-general indicators that determine the conditions for receiving benefits: 'qualification period' and 'duration of unemployment benefits'. Applicants are only eligible to claim benefits if they have contributed for a sufficient period of time and they can only receive these benefits for a specific period.

Unfortunately, data availability poses some limitations, in particular for Eastern-European countries in the year 1990, shortly after the beginning of the transition. No data on replacement rates, qualification period, benefit duration or coverage is available for most Eastern-European countries for this year (see Scruggs et al., 2014). Information on GDP and the change in the unemployment rate is also limited for these countries for 1990. We have to keep this country-year selection bias in mind when comparing results from different years. Some indicators are moderately correlated across countries: GDP growth and the change in the unemployment rate (-0.48), replacement rate and spending (0.45), and GDP and spending (0.44). 


\subsection{Individual-level variables}

To control for the changing composition of the population, we include a number of sociodemographic variables at the individual level. These variables are age, employment status (in five categories: employed, self-employed, unemployed, retired and others such as homemakers and students), gender and education (also in four categories).

\subsection{Methods}

Difficulties arise in empirically testing causal claims about the dynamic relationship between the institutional context, socioeconomic changes and public opinion, because public opinion and social policies are interrelated. Policies feed back into public attitudes, but policies are also the result of public opinion if governments are responsive (Burstein, 2003; Kumlin and Stadelmann-Steffen, 2014). Repeated cross-sectional data, covering roughly two decades, provides some leverage for disentangling these reciprocal effects. However, our empirical strategy mainly relies on cross-national differences at each point in time, while taking into account concurrent changes in economic growth and the unemployment rate.

Because of the cross-national, longitudinal structure of the data, we calculate three-level models in which individuals are nested within country-years (second level) and countries (first level). Economic and institutional indicators are included at the country-year level, therefore they measure the national context at the time of the survey. The number of macro indicators that can be included simultaneously into a multilevel regression is restricted in cross-national research. For this reason, we follow the established approach of including only one macro indicator at a time, whereas in a second step all the indicators that have shown an independent significant effect are included in a joint model.

\section{Results}

\subsection{Economic and institutional indicators, 1990 to 2008}

We begin with a description of the economic and institutional context in the countries at the three time points. Based on our indicators for labour-market spending, unemployment benefit coverage and replacement level, the cross-national variations seem to be more important than simply the trend towards somewhat leaner spending and benefits, as variation across countries is more pronounced than between time points (Table 1). 


\section{[Table 1 about here]}

Although the two decades following 1990 involved major waves of mass unemployment, the three years in which public opinion surveys are available were times of a moderate level of unemployment: 1990 was the first year after the 'fall of the wall' and the beginning of an unemployment wave during the early 1990s in many European, particularly Nordic and Eastern-European, countries; 1999 was shortly before the collapse of the new economy led to a major global recession; 2008 was the year when the financial market crash occurred, but the economic crisis only took hold in the subsequent years. Our analyses of these opinion surveys therefore capture pre-crisis scenarios, before unemployment increased and economic growth declined substantially.

\section{[Figure 1 about here]}

Comparing two important indicators, we find that unemployment benefit coverage varies across Europe (see Figure 1). Most Western-European countries have high levels, except Southern Europe and Finland, whereas the Eastern-European transition economies have low coverage with the exception of the Baltics and the Czech Republic. The replacement rate is relatively low due to flat-rate benefits in the United Kingdom, Poland and the Baltics (Estonia and Lithuania), and only modest in the Czech Republic, Italy, Ireland and Slovakia, whereas all the other countries replace at least 60 per cent of the previous wage. It should be noted that the Nordic countries spend much more on labour-market policy than others, but have a comparably low unemployment rate, whereas some Southern and Eastern-European countries are affected by high unemployment but spend much less.

The post-communist countries changed from a job guarantee under state socialism to a market economy, with higher unemployment and new unemployment protection. Therefore, we assume that respondents in 1990 were still under the expectation of a socialiststyle full employment economy, while facing the uncertainties of a new market economy and a welfare state in the making.

\subsection{Overall level of support}

Our first step in analysing the survey data is to provide a descriptive mapping of the dependent variable at the beginning and end of our time window. Figure 2 displays support 
for conditionality in 1990 (x-axis) and 2008 (y-axis). Countries on the left-hand side of the diagonal had increased public support for conditionality, while those on the right-hand side saw it decreasing (see also Table A1 for data by country and year). We observe low support for conditionality in Eastern Europe in 1990, particularly in Bulgaria and the Baltics, but support for more requirements grew substantially with the continued transition to market economies. Slovenia is a notable exception, as the high support decreased slightly. Public opinion remained supportive of conditionality in most Western-European countries with two exceptions: in Finland, approval dropped by about 1.7 points between 1990 and 1999 and remained low afterwards, following a tripling of the unemployment rate in the 1990s. Support for conditionality fell by about 1.2 points in France after 1999 following the introduction of labour-market reforms in the late 1990s (Arcanjo, 2012).

\section{[Figure 2 about here]}

The shift in public opinion in post-communist nations has led to strong convergence across all the countries in our analysis: the standard deviation of the dependent variable approximately halved from about 1.1 in 1990 to 0.6 in 2008. Although the difference between the countries with the highest and the lowest support for conditionality amounted to about 4.3 points in 1990, this decreased to about 2.2 points in 2008 . These findings are in line with a study by Edlund (2009), who finds a convergence of attitudes in Europe across a number of policy fields.

\subsection{Contextual variables}

The descriptive analysis shows that public opinion towards conditionality varies substantially across countries and has shifted in different directions over time. Turning to our multilevel analysis, the distribution of the variance in an empty three-level model supports this finding (Table 2): 4.1 per cent of the variance is located at the country level and 3.6 per cent at the country-year level. This means that about 8 per cent of the variation in attitudes between individuals can be attributed to the fact that respondents were living in different societies and during specific periods.

\section{[Table 2 about here]}


The next step of our analysis concerns the possible explanations for the differences in public attitudes towards the conditionality of unemployment benefits. As previously outlined, we expect several institutional and economic characteristics to shape public opinion. We test our theoretical assumptions in two steps. First, each indicator is included in separate multivariate models, controlling for composition effects at the individual level. Each of the rows in Model 1 contains the regression estimate for the contextual variable. In the second step, all the indicators that have shown a significant relationship with the dependent variable are included jointly in Model 2 to Model $4 .^{2}$

\subsubsection{Economic indicators}

We first turn to our analysis of the macro-context indicators in Model 1, beginning with the relationship between economic development and support for conditionality. In times of high unemployment, the population is significantly less in favour of forcing the unemployed to take any job. GDP per capita is positively related to support for conditionality. In prosperous economic circumstances, the population is more in favour of demanding additional efforts from the unemployed in exchange for benefits. The explanation for this result might be twofold. First, the jobless could be seen as more deserving when unemployment is widespread and job offers are rare. Second, respondents in work may be more likely to fear losing their job in times of high unemployment and therefore to be subject to stricter conditionality rules when jobless. Even when GDP and the unemployment rate are combined (Model 2), both indicators remain significant, though they reduce in significance when the institutional indicators are added (Model 3 and Model 4). These findings support hypothesis $\mathrm{H} 1 \mathrm{~b}$, indicating a positive relationship between favourable economic circumstances and support for conditionality. This result suggests that deservingness perceptions are shaped by macroscopic assessment of the prevailing labourmarket conditions.

\subsubsection{Institutional indicators}

Next, we investigate the relationship between the institutional nature of the benefit system and the support for conditionality. We argue that the working population might expect more effort from the unemployed when benefits are generous. We find some support for this hypothesis (H3): the replacement rate is significantly positively related to supporting 
more obligations for the unemployed. In countries with more-generous unemployment payments in relation to previous earnings, the population is more in favour of attaching stricter conditions. Therefore, reciprocity seems to play a role for the public: those who get generous benefits are expected to seek a job more quickly. However, this relationship is only significant at the 10 per cent level. Moreover, the spending on unemployment benefits is not related to our dependent variable. Therefore, individuals seem to respond less to the overall budget than to the generosity of benefits, suggesting that it is reciprocity more than taxpayer considerations that matters for deservingness perceptions.

Our next assumption entails that the greater the number of individuals who are potentially affected by stricter conditions, the lower the support for these measures will be. In line with this hypothesis $(\mathrm{H} 4)$, the proportion of the population covered by unemployment benefits is negatively correlated with support for conditionality, albeit only weakly $(p<0.10)$. In some countries, such as Sweden and Slovakia, only approximately two thirds of the population are covered by unemployment benefits and are therefore not affected by conditionality rules regarding lack of access. However, people without access could have a stronger interest in stricter obligations for those receiving unemployment benefits. Interestingly, the effect of the coverage rate actually becomes stronger when controlled for the three other contextual variables (Model 4).

Lastly, the two indicators for the conditions of unemployment benefits - qualification period and duration of benefits - do not show any significant relationship with our dependent variable (H2). In contrast to our expectations, we do not find a positive feedback effect of conditionality on attitudes towards these policies. When taking all the variables together (coverage, replacement rate, GDP and unemployment rate), the model can explain about 89 per cent of the variance at the country level. Notably, although these indicators are included at the country-year level, they contribute little to the explanation of longitudinal changes. These results suggest that the economic and institutional indicators are better suited to explain long-lasting differences between countries than to account for shifts in attitudes over time. 


\section{Conclusion}

Our contribution investigates public attitudes concerning the conditionality for unemployment benefits, comparing 23 countries in Western and Eastern Europe over a period of two decades. In contrast to most previous studies that focus mainly on the rights of the unemployed, we also include the consideration of their responsibilities. The main social policy issue in this respect is whether benefits should be made conditional on the willingness of the unemployed to accept any available job in due time. We find a strong convergence between European countries, largely attributable to a steep increase in support for conditionality in Eastern Europe since public opinion in transition economies became more market-oriented over time. In some of these countries, support augmented about two points on an 11-point scale, indicating an impressive shift towards more responsibilities for the unemployed.

Our multilevel analysis focuses on the relationship with economic development and institutional changes. The main economic indicators - economic growth and the unemployment rate - are significantly related to support for conditionality. People living in wealthier countries are more likely to be in favour of conditionality, whereas a high unemployment rate reduces such support. These findings have implications for policy reforms. Access to unemployment benefits is often restricted in times of economic downturns when reform pressure is highest. However, our results show that support for conditions is at its lowest in times of economic decline. Therefore, perceived deservingness seems to be dependent on the prevailing economic context.

With regard to institutional features, the most striking finding is the negative relationship between the coverage rate and support for stricter conditions. Our interpretation of this finding is that when more individuals could be potentially affected by these conditions, support for the measures decreases. We also find some support for the assumption that people in welfare states with more-generous social policies prefer stricter conditionality for access in order to protect the generous benefits against any misuse. This poses the question of whether we can infer that a growing economy and expanding welfare system in postcommunist countries have led to the convergence of attitudes. An alternative explanation could be that these societies have undergone a dramatic transition from a socialist to a 
market economy. Whereas the state used to be responsible from the cradle to the grave, the sudden transition to a capitalist market economy introduced more responsibilities for the individual in line with more-liberal market discourse.

Our findings are subject to some limitations. First, our ability to infer strong claims about the causal relationship between social policies and public opinion is limited by the large time gaps between the three survey rounds. Second, our measurement for conditionality is far from perfect, and future surveys should use a refined measurement of the conditions for entitlement to unemployment benefits. Third, we cannot test whether respondents at different points in time in diverse countries understand the questions about conditions for benefits in a similar or instead a context-specific way. However, we are confident that the basic principle of conditionality is fairly similar across time and between nations, although this certainly needs further research to validate.

Overall, our cross-national results over time provide further evidence that the economic and institutional context influences perceptions of deservingness. The unemployed are seen as more deserving of unconditional benefits in times of economic downturn and when benefits are less generous. Based on this evidence, we have shown that deservingness theory contributes to a better understanding of attitude changes over time and to the differences between countries. 


\section{References}

Achterberg, P., Van der Veen, R., \& Raven, J. (2014). The ideological roots of the support for welfare state reform: Support for distributive and commodifying reform in The Netherlands. International Journal of Social Welfare, 23(2), 215-226.

Arcanjo, M. (2012). Unemployment Insurance Reform - 1991-2006: A new balance between rights and obligations in France, Germany, Portugal and Spain. Social Policy \& Administration, 46(1), 1-20.

Blekesaune, M., \& Quedagno, J. (2003). Public attitudes toward welfare state policies: A comparative analysis of 24 nations. European Sociological Review, 19(5), 415-427.

Brooks, C., \& Manza, J. (2007). Why welfare states persist: The importance of public opinion in democracies. Studies in communication, media, and public opinion. Chicago: University of Chicago Press.

Burstein, P. (2003). The impact of public opinion on public policy: A review and an agenda. Political Research Quarterly, 56(1), 29-40.

Clasen, J., \& Clegg, D. (Eds.) (2011) Regulating the risk of unemployment: National adaptations to postindustrial labour markets in Europe. Oxford: Oxford University Press.

Durr, R. H. (1993). What moves policy sentiment? The American Political Science Review, 87(1), 158-170.

Dwyer, P. (2004). Creeping conditionality in the UK: From welfare rights to conditional entitlements? The Canadian Journal of Sociology, 29(2), 265-287.

Edlund, L. (2009). Attitudes towards state organized welfare in 22 societies: A question of convergence? In M. Haller, R. Jowell, \& T. W. Smith (Eds.), The international social survey programme, 1984-2009. London: Routledge.

Estevez-Abe, M., Iversen, T., \& Soskice, D. (2001). Social protection and the formation of skills: A reinterpretation of the welfare state. In P. A. Hall \& D. W. Soskice (Eds.), Varieties of capitalism. The institutional foundations of comparative advantage. New York: Oxford University Press.

Fraile, M., \& Ferrer, M. (2005). Explaining the determinants of public support for cuts in unemployment benefits spending across OECD countries. International Sociology, 20(4), 459-481.

Fridberg, T., \& Ploug, N. (2000). Public attitudes to unemployment in different European welfare regimes. In D. Gallie \& S. Paugam (Eds.), Welfare regimes and the experience of unemployment in Europe (pp. 334-350). Oxford : Oxford University Press.

Gusmano, M. K., Schlesinger, M., \& Thomas, T. (2002). Policy feedback and public opinion: The role of

employer responsibility in social policy. Journal of Health Politics, Policy and Law, 27(5), 731-772.

Hall, P. A., \& Taylor, R. C. (1996). Political science and the three new institutionalisms. Political Studies, 44, 936-957.

Handler, J. F. (2003). Social citizenship and workfare in the US and Western Europe: From status to contract. Journal of European Social Policy, 13(3), 229-243.

Houtman, D. (1997). Welfare state, unemployment, and social justice: Judgments on the rights and obligations of the unemployed. Social Justice Research, 10(3), 267-288.

Jæger, M. M. (2006). What Makes People Support Public Responsibility for Welfare Provision: Selfinterest or Political Ideology?: A Longitudinal Approach. Acta Sociologica, 49(3), 321-338.

Jeene, M., \& van Oorschot, W. (2014). The relative deservingness of the unemployed in the eyes of the European public. In W. A. Arts \& L. Halman (Eds.), European Values Studies: volume 15. Value contrasts and consensus in present-day Europe. Painting Europe's moral landscapes.

Jeene, M., van Oorschot, W., \& Uunk, W. (2014). The dynamics of welfare opinions in changing economic, institutional and political contexts: An empirical analysis of Dutch deservingness opinions, 1975-2006. Social Indicators Research, 115(2), 731-749. 
Knotz, C. M. (2015). How thight are the scres? Obligations and sanctions for the unemployed in OECD countries, 1980-2012. Manuscript.

Kumlin, S., \& Stadelmann-Steffen, I. (Eds.). (2014). How welfare states shape the democratic public: Policy feedback, participation, voting, and attitudes. Edward Elgar Publishing.

Larsen, C. A. (2007). The institutional logic of welfare attitudes: How welfare regimes influence public support. Comparative Political Studies, 41(2), 145-168.

Larsen, C. A. (2008). The political logic of labour market reforms and popular images of target groups. Journal of European Social Policy, 18(1), 50-63.

Margalit, Y. (2013). Explaining social policy preferences: Evidence from the great recession. American Political Science Review, 107(01), 80-103.

Marshall, T. H. (1950). Citizenship and social class. Cambridge: Cambridge University Press.

Mau, S. (2003). The moral economy of welfare states: Britain and Germany compared. London: Routledge.

Myles, J., \& Pierson, C. (2001). The comparative political economy of pension reform. In P. Pierson (Ed.), The new politics of the welfare state (pp. 305-333). Oxford: Oxford University Press.

Naumann, E., Buss, C., \& Bähr, J. (2016). How unemployment experience affects support for the welfare state: A real panel approach. European Sociological Review, 32(1), 81-92.

Pierson, P. (1993). When effect becomes cause: Policy feedback and political change. World Politics, 45(04), 595-628.

Scruggs, L., Jahn, D. \& Kuitto, K. (2014) Comparative Welfare Entitlements Dataset 2. Version 2014-03. University of Connecticut \& University of Greifswald. [http://cwed2.org/]

Svallfors, S. (2010): Public attitudes. In: Francis G. Castles et al. (eds.), The Oxford Handbook of the Welfare State. Oxford: Oxford University Press, 241-251.

Svallfors, S. (2011). A bedrock of support?: Trends in welfare state attitudes in Sweden, 1981-2010. Social Policy \& Administration, 45(7), 806-825.

van Oorschot, W. (2006). Making the difference in social Europe: deservingness perceptions among citizens of European welfare states. Journal of European Social Policy, 16(1), $23-42$.

van Oorschot, W., \& Meuleman, B. (2014). Popular deservingness of the unemployed. Effects of policy context, economic and cultural climate. In S. Kumlin \& I. Stadelmann-Steffen (Eds.), How Welfare States Shape The Democratic Public. Policy Feedback, Participation, Voting and Attitudes. Cheltenham: Edward Elgar Publishing.

Wendt, C., Mischke, M. \& Pfeifer, M (2011). Welfare states and public opinion. Perceptions of healthcare systems, family policy and benefits for the unemployed and poor in Europe. Cheltenham: Edward Elgar Publishing.

Weishaupt, J. T. (2011). From the manpower revolution to the activation paradigm. Explaining institutional continuity and change in an integrating Europe. Amsterdam: Amsterdam University Press. 
Figure 1: Macro indicators for coverage and replacement rate in 1999

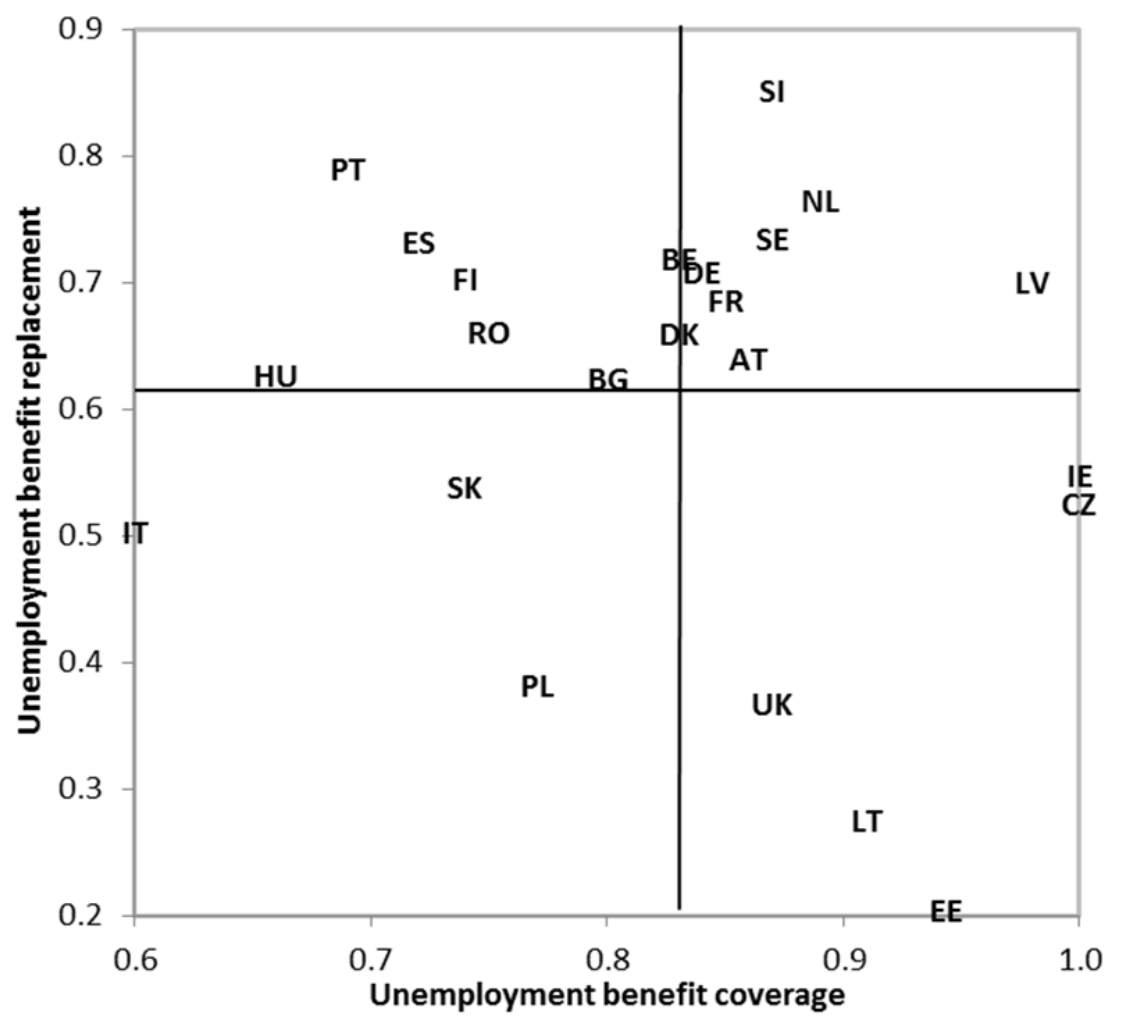

Source: Comparative Welfare Entitlements Dataset (CWED 2) and own estimates for coverage of some Eastern-European countries based on later years.

Note: $\mathrm{x}$-scale refers to replacement rate in per cent of previous net wage and y-scale refers to per cent of the work force covered by unemployment insurance. Country codes: AT Austria, BE Belgium, BG Bulgaria, CZ Czech Republic, DE Germany, DK Denmark, EE Estonia, ES Spain, FI Finland, FR France, HU Hungary, IE Ireland, IT Italy, LT Lithuania, LV Latvia, NL Netherlands, PL Poland, PT Portugal, RO Romania, SE Sweden, SI Slovenia, SK Slovak Republic, UK United Kingdom. 
Figure 2: Mean support for conditionality in 1990 and 2008

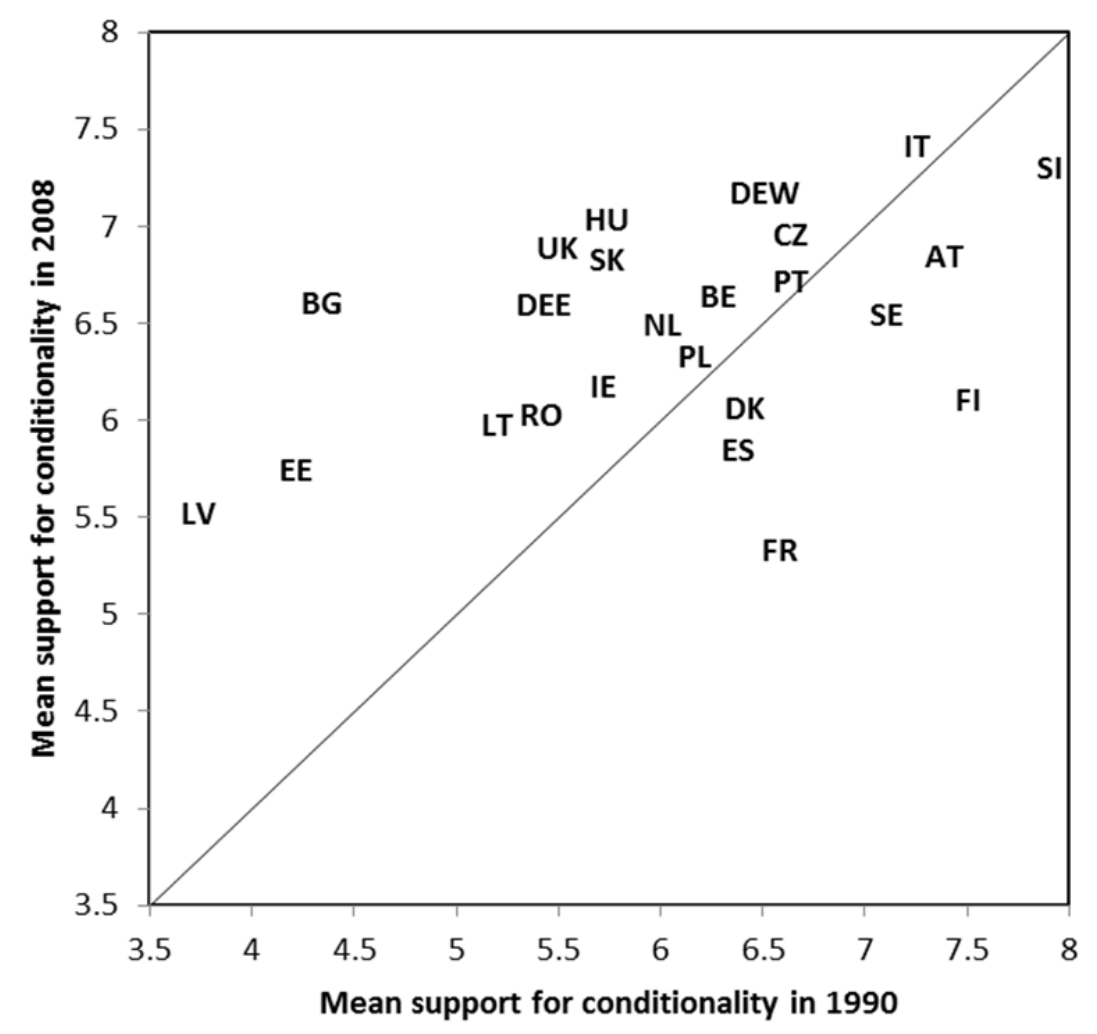

Source: EVS 1990 and 2008, own analysis. Note: DEW West Germany, DEE East Germany. 
Table 1: Descriptive statistics for institutional and economic indicators in 1990, 1999 and 2008

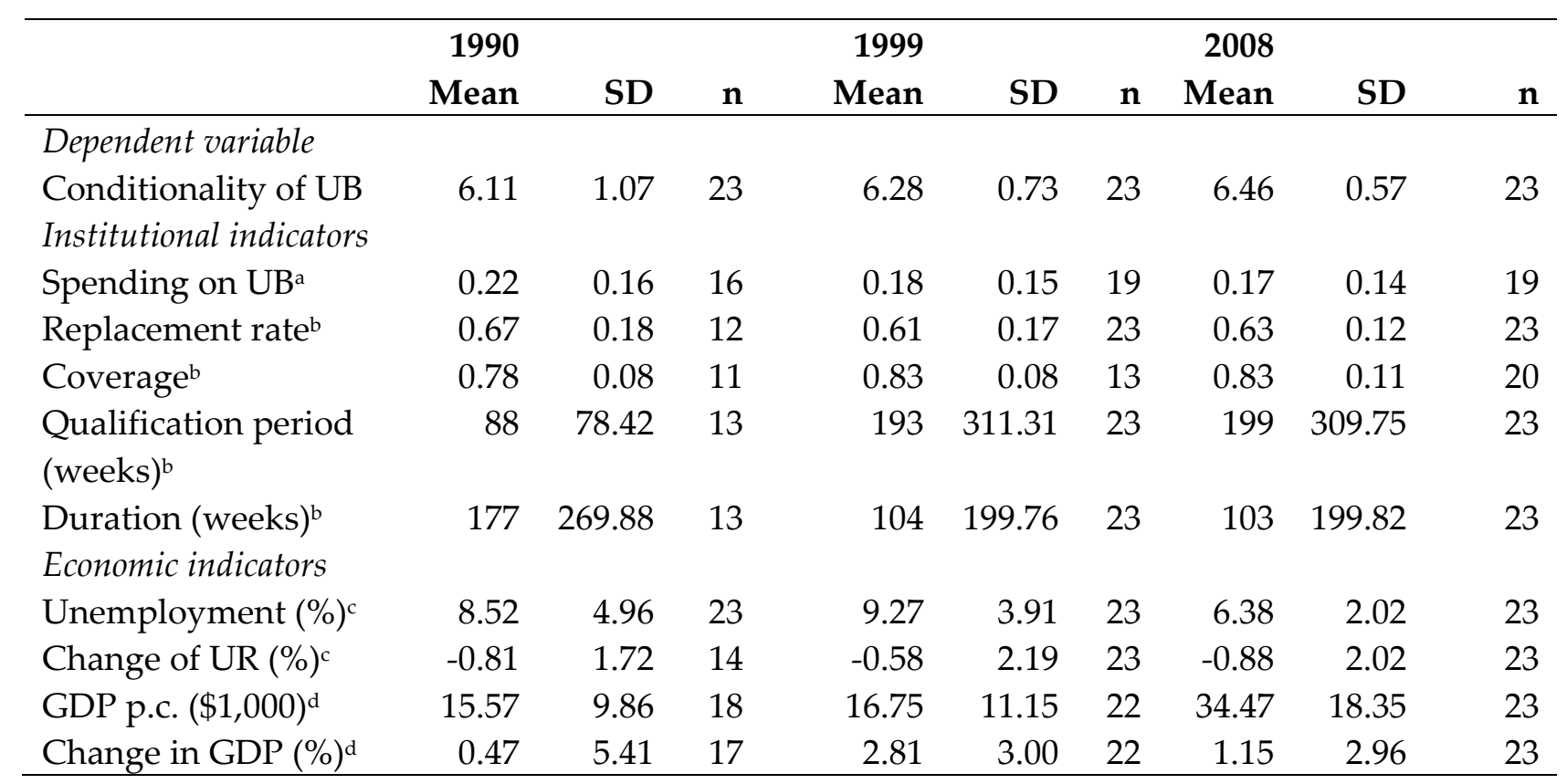

Notes:

Standard deviation (SD) calculated on the country level.

Spending on UB: passive labour market policies, divided by GDP and the unemployment rate.

Replacement rate for a family with two children.

UR: unemployment rate.

GDP p.c.: GDP per capita.

Sources: a: OECD, own calculation; b: CWED by Scruggs, Jahn and Kuitto (2014); c: ILO; d:

World Bank. 
Table 2: Influence of institutional and economic indicators on public support for the conditionality of unemployment benefits, three-level regression models

\begin{tabular}{|c|c|c|c|c|c|}
\hline & Empty & Model 1 & Model 2 & Model 3 & Model 4 \\
\hline \multicolumn{6}{|l|}{ Economic indicators } \\
\hline Unemployment rate & -- & $-0.06^{* *}$ & $-0.04+$ & -0.02 & -0.04 \\
\hline Change of UR & -- & 0.00 & -- & -- & -- \\
\hline GDP per capita (log) & -- & $0.25^{* *}$ & $0.18+$ & 0.11 & -0.04 \\
\hline GDP change & -- & 0.03 & -- & -- & -- \\
\hline \multicolumn{6}{|l|}{ Institutional indicators } \\
\hline UE coverage & -- & $-1.66+$ & -- & -- & $-1.83^{* *}$ \\
\hline Spending on UB & -- & 0.45 & -- & -- & -- \\
\hline Replacement rate & -- & $1.03+$ & -- & 0.88 & 0.43 \\
\hline UB qualification period & -- & 0.00 & -- & -- & -- \\
\hline UB duration & -- & 0.00 & -- & -- & -- \\
\hline N (country-year) & 69 & -- & 63 & 57 & 43 \\
\hline $\begin{array}{l}\text { Individual-level } \\
\text { variables }\end{array}$ & No & Yes & Yes & Yes & Yes \\
\hline \multicolumn{6}{|l|}{ Variance components } \\
\hline Country level & 0.33 & & 0.15 & 0.19 & 0.04 \\
\hline Country-year level & 0.29 & & 0.21 & 0.16 & 0.21 \\
\hline \multicolumn{6}{|l|}{ Explained variance } \\
\hline $\mathrm{R}^{2}$ country level & -- & -- & $54.5 \%$ & $41.5 \%$ & $88.5 \%$ \\
\hline
\end{tabular}

$+\mathrm{p}<0.1,{ }^{*} \mathrm{p}<0.05,{ }^{* *} \mathrm{p}<0.01,{ }^{* * *} \mathrm{p}<0.001$

Notes:

Model 1: Country-level factors are included in separate three-level regression models.

$\mathrm{N}$ (country-year) differs between 44 (coverage) and 69 (unemployment rate).

For information on date availability please refer to Table 1.

All models control for age, employment status, gender and education.

\footnotetext{
${ }^{1}$ The survey was conducted at slightly later points in time in Austria, Bulgaria, the Czech Republic, Hungary, Slovakia (all in 1991), Romania (1993), Slovenia (1992), Belgium (2009) and Finland (2000 and 2009).

${ }^{2}$ To investigate if the relationship between indicators and attitudes is consistent over time, Table A2 in the online appendix presents regression results for each year separately.
} 